\title{
BMJ Open Descriptive analysis of a 1:1 physiotherapy outpatient intervention post primary lumbar discectomy: one arm of a small-scale parallel randomised controlled trial across two UK sites
}

\author{
A Rushton, ${ }^{1}$ A Calcutt, ${ }^{2} \mathrm{~N}$ Heneghan, ${ }^{1}$ A Heap, ${ }^{3}$ L White, ${ }^{3}$ M Calvert, ${ }^{4} \mathrm{P}$ Goodwin ${ }^{5}$
}

To cite: Rushton A,

Calcutt A, Heneghan N, et al. Descriptive analysis of a 1:1 physiotherapy outpatient intervention post primary lumbar discectomy: one arm of a small-scale parallel randomised controlled trial across two UK sites. BMJ Open 2016;6:e12151. doi:10.1136/bmjopen-2016012151

- Prepublication history and additional material is available. To view please visit the journal (http://dx.doi.org/ 10.1136/bmjopen-2016012151).

Received 5 April 2016 Revised 16 August 2016 Accepted 17 October 2016

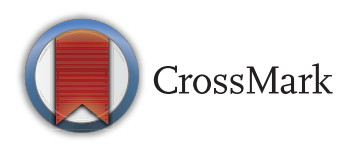

For numbered affiliations see end of article.

Correspondence to Dr Alison Rushton; a.b.rushton@bham.ac.uk

\section{ABSTRACT}

Objective: There is a lack of high-quality evidence for physiotherapy post lumbar discectomy. Substantial heterogeneity in treatment effects may be explained by variation in quality, administration and components of interventions. An optimised physiotherapy intervention may reduce heterogeneity and improve patient benefit. The objective was to describe, analyse and evaluate an optimised 1:1 physiotherapy outpatient intervention for patients following primary lumbar discectomy, to provide preliminary insights.

Design: A descriptive analysis of the intervention embedded within an external pilot and feasibility trial. Setting: Two UK spinal centres.

Participants: Participants aged $\geq 18$; post primary, single level, lumbar discectomy were recruited.

Intervention: The intervention encompassed education, advice, mobility and core stability exercises, progressive exercise, and encouragement of early return to work/activity. Patients received $\leq 8$ sessions for $\leq 8$ weeks, starting 4 weeks post surgery (baseline). Outcomes: Blinded outcome assessment at baseline and 12 weeks (post intervention) included the Roland Morris Disability Questionnaire. STarT Back data were collected at baseline. Statistical analyses summarised participant characteristics and preplanned descriptive analyses. Thematic analysis grouped related data.

Findings: Twenty-two of 29 allocated participants received the intervention. STarT Back categorised $n=16$ $(55 \%)$ participants 'not at low risk'. Physiotherapists identified reasons for caution for $8(36 \%)$ participants, commonly risk of overdoing activity $(n=4,18 \%)$. There was no relationship between STarT Back and physiotherapists' evaluation of caution. Physiotherapists identified 154 problems (mean (SD) 5.36 (2.63)). Those 'not at low risk', and/or requiring caution presented with more problems, and required more sessions (mean (SD) 3.14 (1.16)).

Conclusions: Patients present differently and therefore require tailored interventions. These

\section{Strengths and limitations of this study}

- The study employed a rigorous process to analyse and evaluate an optimised 1:1 physiotherapy outpatient intervention for patients following primary lumbar discectomy.

- To reflect current practice, the nine-item STarT Back may have been more valuable to avoid reducing the tool's discriminative power.

- Although specific interventions were indicated as used, free text sections were often left unanswered thereby limited depth of information was gained, perhaps reflecting the increasing demands placed on National Health Service physiotherapists.

- The study conclusions are limited by the low numbers of patients but some valuable insights can now be used to develop further work.

differences may be identified using clinical reasoning and outcome data.

Trial registration number: ISRCTN33808269; post results.

\section{INTRODUCTION}

With a lifetime prevalence of $80 \%$, low back pain (LBP) represents a considerable health issue $^{1}$ with extensive financial (estimated $£ 10668$ million annually) and societal cost. ${ }^{2}$ Surgical management is the largest single component of expenditure, with lumbar discectomy a common procedure to excise part of a prolapsed intervertebral disc for a primary indication of leg pain. ${ }^{3}$ Data support high numbers of patients undergoing surgery, with 8478 operations performed within the UK National Health Service 
(NHS) in the 2013/2014 year ${ }^{4}$ and annual estimates of 12000 in the Netherlands, ${ }^{5}$ and 287122 in the USA. ${ }^{6}$ Lumbar discectomy is considered effective, with documented success of $46-75 \%$ at $6-8$ weeks, and $78-95 \%$ at 1-2 years post surgery. ${ }^{3}$

However, evidence suggests ongoing disability for some patients, with $70 \%$ fit to return to work 12 months after surgery ${ }^{7}$ and $30-70 \%$ experiencing residual pain. ${ }^{8}$ Reoperation is also an issue, estimated as $3-12 \%$ patients in the Netherlands, ${ }^{9}$ and $14 \%$ in the UK. ${ }^{4}$ With a low mean working age of 45 years for patients undergoing surgery and short mean hospital stay of 2.3 days, ${ }^{4}$ postoperative outpatient rehabilitation is a key issue.

Post operative advice and rehabilitation is variable from surgeon $^{10}$ and physiotherapist perspectives. ${ }^{11}$ In some spinal centres $(44 \%)$, individual outpatient physiotherapy is provided for all patients, and in others only for patients experiencing residual problems (further $46 \%$ centres). ${ }^{11}$ Content and advice of physiotherapy management were variable, with 1-20 sessions and a wide range of interventions advocated.

Our systematic review ${ }^{12}$ focused on the effectiveness of physiotherapy outpatient intervention post first single level lumbar discectomy. Only 1 of 16 included trials was low risk of bias, and only 3 trials investigated individualised physiotherapy outpatient management, reflective of current practice $^{11}$ in several countries including the UK. The others investigated group management. Evidence was inconclusive overall. Some evidence suggested physiotherapy improved disability, with a potential benefit of more intensive intervention; and weak evidence suggested improved movement/physical impairment; all in the short-term. The findings mirrored a recently updated Cochrane review that investigated effectiveness of rehabilitation programmes that included physiotherapy. ${ }^{3}$ Only 10 of 22 included trials were low risk of bias. Of particular interest, is a potential positive effect of exercise on pain and function; with very low/ low quality evidence supporting high>low intensity exercise programmes short term, and low quality evidence supporting physiotherapy starting at 4-6 weeks compared with no treatment/education only. The evidence from their previous review ${ }^{13}$ of $n=14$ trials had been stronger, with low to moderate evidence supporting effectiveness of exercise compared with no treatment, and high intensity exercises as more effective than low intensity for pain and improved physical impairment.

These data raise questions regarding optimal rehabilitation. An adequately powered low risk of bias trial is required to identify whether individualised physiotherapy is effective/cost-effective. Substantial heterogeneity in treatment effects across all systematic reviews could be explained by variation in quality, administration and components of interventions, illustrated by the documented variability in management and advice. ${ }^{10} 11$ Therefore, prior to planning a trial, an optimised 1:1 physiotherapy outpatient intervention was developed through a rigorous process ${ }^{14}$ to reflect best practice, with flexibility to tailor management to individual patients in line with Medical Research Council (MRC) guidance regarding the development of complex interventions (see online supplementary file S1). ${ }^{15}$ The intervention was evaluated through an external pilot and feasibility study ${ }^{16}$ that enabled description and analysis of the intervention and physiotherapist decision-making.

\section{Objective}

To describe, analyse and evaluate application of the optimised 1:1 physiotherapy outpatient intervention for patients following primary lumbar discectomy.

\section{METHODS}

\section{Design and setting}

A descriptive analysis of the optimised (designed to reflect best practice) 1:1 physiotherapy outpatient intervention embedded within an external pilot and feasibility study in preparation for a randomised controlled trial (RCT) reported elsewhere. ${ }^{16}$ This was a descriptive analysis of one arm of a small-scale parallel RCT design, randomising consenting patients across two UK sites, the Queen Elizabeth Hospital Birmingham (QEHB) and the Salford Royal Foundation Trust (SRFT), to either the optimised intervention including patient leaflet or patient leaflet alone. The two sites delivered the same intervention (as far as could be standardised) and for this reason and owing to low numbers, there was no intention to compare between sites.

\section{Participants}

\section{Eligibility criteria}

Patients aged $>18$ years; post primary, single level, lumbar discectomy (including microdiscectomy), ${ }^{17}$ and able to communicate in English. Exclusion criteria: previous surgery at same spinal level; comorbidities that might impact on ability to participate in interventions including cauda equina compression, cognitive dysfunction, uncontrolled cardiovascular disease, ${ }^{17}$ osteoporotic fracture, spondylolisthesis, multiple sclerosis, tumour; ${ }^{18}$ complications from surgery; ${ }^{17} 19$ and participation in a concurrent trial.

\section{Recruitment}

Patients at both sites were invited to participate prior to discharge. Interested and eligible patients were provided with a Participant Information Sheet, their questions answered, and asked to provide written consent to be contacted with an appointment 4 weeks post surgery. The patient leaflet was provided and discussed. At 4 weeks, written informed consent was gained from eligible patients, and patients were randomised. The patient leaflet is described elsewhere. ${ }^{20}$

\section{Ethics approval}

R\&D approval was gained. The West Midlands-Solihull Research Ethics Committee granted ethical approval (reference number 12/WM/0224). 


\section{Physiotherapy intervention}

The 1:1 physiotherapy outpatient intervention (detailed in online supplementary file 1) encompassed education, advice, mobility exercises, core stability exercises, a progressive approach to exercise to increase intensity and encouragement of early return to work/activity. It was designed $^{14}$ to reflect best practice, based on current evidence, ${ }^{10-13}$ and enabled the physiotherapist to select components of the intervention that best addressed the individual patient's problems. It was developed and agreed by the research team following consultation with clinical experts and spinal surgeons at five spinal centres, physiotherapists and patients; and is fully reported elsewhere. ${ }^{14}$ This ensured an intervention informed by the evidence base that discouraged the use of treatments for which there is evidence of no effect. Although developed prior to the recently updated Cochrane review, ${ }^{3}$ the intervention remains consistent with best evidence. Patients could attend $\leq 8$ physiotherapy sessions $\leq 8$ weeks, allowing patient choice and local practice variation.

The intervention started 4 weeks post surgery to provide optimal care. ${ }^{3}{ }^{12}$ First, a list of guiding principles provided the basis for and guided the individual physiotherapist's decisions for selecting treatment content, dose and progression, etc. Second, a table of dual purpose provided a description of the intervention and structure to enable physiotherapists to record the delivered intervention. In line with MRC guidance, ${ }^{15}$ the intervention incorporated flexibility to tailor management to individual patient's needs following the physiotherapist's assessment of the individual patient and identification of their problems; ensuring patient centred care based on clinical reasoning. Physiotherapy clinical reasoning is complex and many trial interventions fail to capture and describe these processes. The developed intervention was acceptable to patients and clinicians. ${ }^{1416}$

\section{Demographic data and outcome assessment}

Blinded outcome assessment was 4 weeks after surgery (baseline), and following intervention at 12 weeks postbaseline ( primary end point). Demographic data including age, gender, duration of symptoms prior to surgery, planned or emergency surgery, presence of leg and/or back pain, analgesia, employment status and ethnicity were collected to describe participant characteristics. The primary outcome was the Roland Morris Disability Questionnaire (RMDQ), and the choice of secondary measures was informed by patients, surgeons and physiotherapists: Global Perceived Effect (GPE) (1=completely recovered, $2=$ much improved, $3=$ slightly improved, $4=$ not changed, $5=$ =slightly worse, $6=$ much worse and $7=$ =worse than ever compared with presurgery), Visual Analogue Scale leg pain and back pain $(0-10 \mathrm{~cm}$, with 0 'no pain' and 10 'worst pain ever'), EQ-5D 5L, time to return to work/normal function/full duty, Tampa Scale for Kinesiophobia (17 items, each rated as 1 'strongly disagree', 2 'disagree', 3 'agree', or, 4 'strongly agree', total score out of 68), Fear Avoidance and Beliefs Questionnaire (FABQ) (16 items rated 0-6 informing two subscales: FABQ physical activity total score 24 , and FABQ work 42), Straight Leg Raise, range of lumbar movement, analgesia and reoperation. ${ }^{16}$ Adherence was measured. The outcomes at 4 and 12 weeks post surgery are reported in full elsewhere ${ }^{14}$ and results were promising for both interventions.

\section{Keele STarT Back tool}

The Keele STarT Back tool was also part of data collection at baseline. ${ }^{21}$ It was developed for patients presenting with LBP in primary care to inform stratification of care based on identification of barriers to recovery. The tool possesses high reliability, ${ }^{21}$ and validity compared to the Örebro Musculoskeletal Pain Screening Questionnaire. $^{22}$ Researchers have investigated the predictive value of STarT Back in secondary care, in physical therapy clinics in $\mathrm{USA}^{23} 24$ and Danish specialist care; ${ }^{25} 26$ finding it less effective than in primary care, but equivalent to other measures such as pain intensity or activity limitation. The six-item tool was used for consideration of participant questionnaire burden (referred leg pain, disability, catastrophising, depression and overall impact items) that stratifies patients into low risk/not at low risk of poor outcome. It has not been validated in a post operative population and was therefore used descriptively in this study to provide preliminary data.

\section{Physiotherapists}

Eligible treating physiotherapists were any band (grade) and working within the outpatient department. They were blinded to baseline STarT Back and outcome measure data. Training (from AR/PG) standardised intervention delivery and answered questions.

\section{Detail of intervention data collection}

Physiotherapists and service users informed the development of the data collection tool that enabled capture of key components of the physiotherapy assessment to inform delivery of the intervention ${ }^{14}$ (see online supplementary file 1 ).

\section{Data analysis}

Data were transferred to SPSS (V.21, IBM, New York, New York, USA) and all data were checked to ensure their integrity. Statistical analyses included a summary of participant characteristics and pre-planned descriptive analyses. Thematic analysis was used to group related data ${ }^{27}$ to enable descriptive analysis that explored: demographics, treatment detail and whether physiotherapists identified a need for caution (aspects of clinical reasoning), and STarT Back data; in the context of treatment duration, frequency of interventions, problems identified, number of sessions and discharge data. 


\section{FINDINGS}

\section{Participants}

The study ran from January 2013 to July 2014, inclusive of recruitment, intervention, outcome assessment and focus groups. Figure 1 presents the trial Consolidated Standards of Reporting Trials (CONSORT) diagram. Twenty-nine patients were randomly allocated to the 1:1 physiotherapy and patient leaflet intervention ( $\mathrm{n}=11$ QEHB, $\mathrm{n}=18$ SRFT), and their characteristics are detailed in table 1 . The recruitment factor was 25/77 (32\%) at the QEHB site (randomised/introduced) and 34/175 (19\%) at the SRFT site; travel was the key issue for patients not interested in participating.
Most surgical procedures were planned and the mean age of participants reflects a working population with $83 \%$ participants working (employed/self-employed). At the 4 -week baseline $28 \%(\mathrm{n}=8)$ were back at work. The mean duration of symptoms prior to surgery was 61 months. Table 2 illustrates the clinical presentation of participants. All participants presented with pain and the majority with leg pain $(93 \%)$ prior to surgery. Paraesthesia and numbness were common. At baseline, participants presented overall as moderate disability and although pain was mostly of low severity at this point, most required analgesia. The median GPE of 2 reflected considerable improvement from the surgery, perhaps also reflected in the high health related quality of life

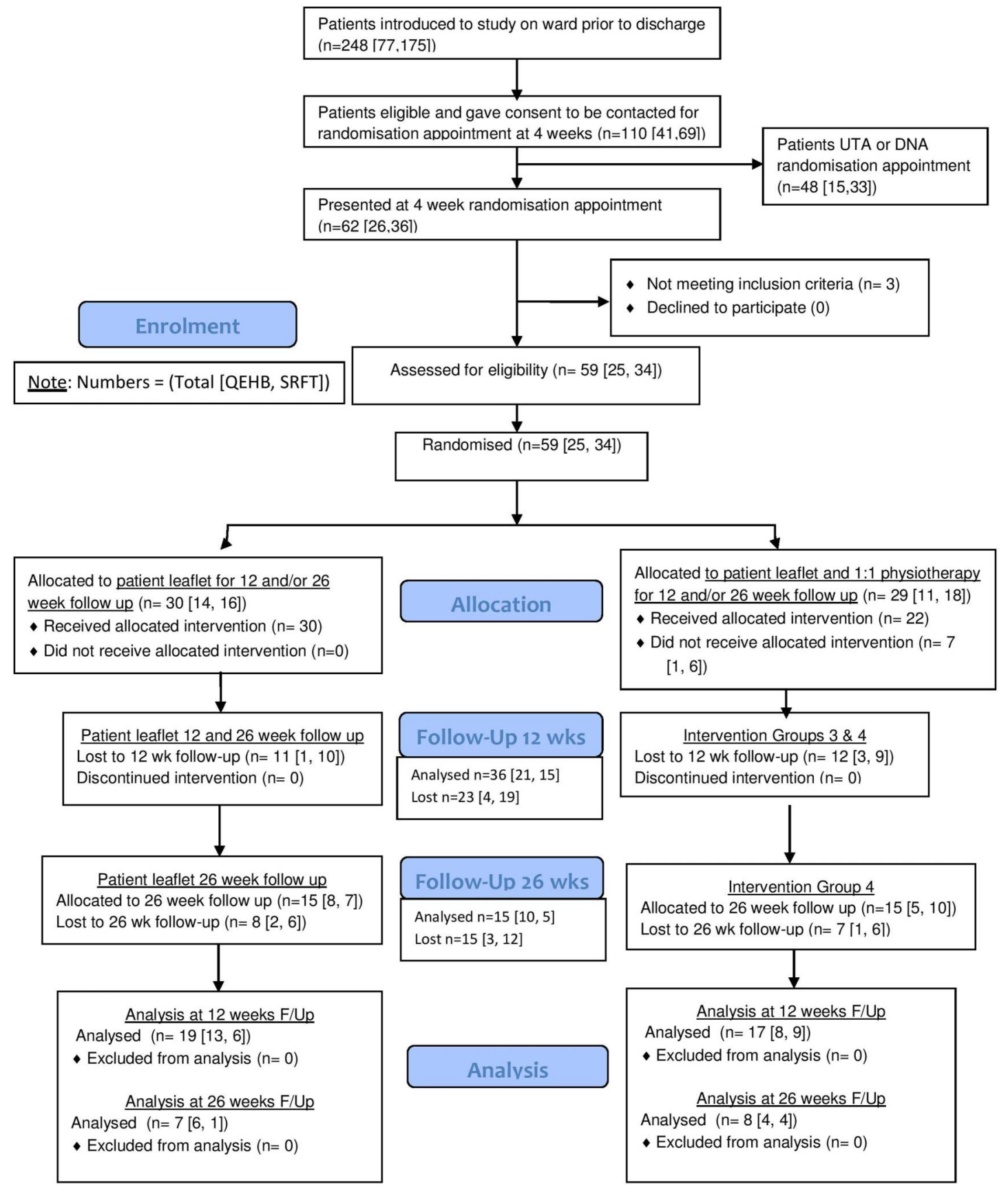

Figure 1 CONSORT diagram. CONSORT; Consolidated Standards of Reporting Trials. 
Table 1 Baseline participant characteristics 1:1 physiotherapy/patient leaflet intervention group

\begin{tabular}{|c|c|c|c|}
\hline \multicolumn{2}{|l|}{ Characteristic } & \multirow{2}{*}{$\begin{array}{l}\mathbf{n}^{*} \\
29\end{array}$} & \multirow{2}{*}{$\begin{array}{l}\text { Participants } \\
17: 12\end{array}$} \\
\hline \multirow{2}{*}{\multicolumn{2}{|c|}{$\begin{array}{l}\text { Gender (male : female) } \\
\text { Age in vears (roge mean+SD) }\end{array}$}} & & \\
\hline & & 29 & $26-64,44.04 \pm 9.79$ \\
\hline \multicolumn{2}{|c|}{ Nature of surgery (planned : emergency) } & 29 & $26: 3$ \\
\hline \multirow[t]{3}{*}{ Ethnic group } & White Caucasian & 28 & 25 \\
\hline & Other white background & & 1 \\
\hline & Indian & & 2 \\
\hline \multirow[t]{5}{*}{ Employment status } & Employed & 28 & 15 ( $n=1$ also part-time student) \\
\hline & Self-employed & & 8 \\
\hline & Unemployed & & 2 \\
\hline & Retired & & 2 \\
\hline & Other (teaching contract ending) & & 1 \\
\hline \multirow[t]{8}{*}{ Income band } & $<£ 10000$ & 27 & 2 \\
\hline & $£ 10000-19999$ & & 7 \\
\hline & $£ 20000-29999$ & & 7 \\
\hline & $£ 30000-39999$ & & 4 \\
\hline & $£ 40000-49999$ & & 1 \\
\hline & $£ 50000-59999$ & & 3 \\
\hline & $£ 60000-69999$ & & 0 \\
\hline & $>£ 70000$ & & 3 \\
\hline \multirow{3}{*}{ Claims } & Employer sick pay & 29 & 13 \\
\hline & Statutory sick pay & 29 & 6 \\
\hline & Disability living allowance & 29 & 1 \\
\hline \multicolumn{2}{|c|}{ Duration of symptoms prior to surgery (mean months $\pm S D$ ) } & 29 & $68.34 \pm 93.80$ \\
\hline \multirow{3}{*}{\multicolumn{2}{|c|}{ Returned to work }} & 28 & Yes 8 \\
\hline & & & No 19 \\
\hline & & & Not applicable 1 \\
\hline \multirow{3}{*}{\multicolumn{2}{|c|}{ Duties }} & 29 & Full duties 3 \\
\hline & & & Light duties 4 \\
\hline & & & Not applicable 22 \\
\hline \multirow{3}{*}{\multicolumn{2}{|c|}{$\begin{array}{l}\text { Full-time or part-time working (prior to surgery, } 17 \text { were full-time, } \\
6 \text { part-time and not applicable for } 5 \text { (missing data for } 1 \text { ) }\end{array}$}} & 29 & Full-time 6 \\
\hline & & & Part-time 2 \\
\hline & & & Not applicable 21 \\
\hline \multicolumn{2}{|c|}{ Weeks returned to work $(\operatorname{mean} \pm S D)$} & 28 & $3.81(1.60)$ \\
\hline \multicolumn{2}{|c|}{ Returned to normal activity (yes:no) } & 29 & $7: 22$ \\
\hline \multicolumn{2}{|c|}{ Weeks returned to normal activity (mean \pm SD) } & 27 & $3.21(1.63)$ \\
\hline
\end{tabular}

scores. Patients presented with a high TAMPA reflecting issues of kinesiophobia.

The STarT Back data (table 3) illustrate that $\mathrm{n}=16$ (55\%) participants scored $\geq 3$ and would be categorised as not at low risk of chronicity/poor recovery and therefore physiotherapy would be recommended.

Of the $n=29$ participants allocated to the optimised intervention, $\mathrm{n}=22$ received the intervention. $\mathrm{N}=1$ QEHB and $n=6$ SRFT did not receive the intervention (five female, two male), and five of seven were categorised not at low risk using STarT Back. No adverse events were reported and no participant required further surgery.

\section{Treating physiotherapist assessment of $n=22$ participants} who received the intervention

Eight participants $(36 \%)$ had reasons for caution identified by the physiotherapists, the most common being at risk of overdoing activity $(\mathrm{n}=4,18 \%)$ through returning to work early $(n=1)$, keen to return to heavy work/ weight training $(\mathrm{n}=1)$, tendency to overdo exercise $(\mathrm{n}=1)$, and diagnosis of post-traumatic stress disorder, using training as a coping strategy $(\mathrm{n}=1)$. Other reasons included: care with neural mobilisations as assessment of SLR exacerbated pain for 4 days, previous trauma and orthopaedic surgery of left hip and right foot, and normal precautions. There was no relationship between STarT Back and the physiotherapist's evaluation of caution $(50 \%$ of those evaluated as requiring caution were evaluated as low risk).

\section{Physiotherapy diagnosis}

Table 4 details the physiotherapy diagnoses grouped according to the nature of the diagnosis.

\section{Participants' problems}

Treating physiotherapists highlighted a total of 154 problems (mean 5.36, SD 2.63). Those categorised as STarT Back not at low risk, and those evaluated as requiring caution by physiotherapists presented with a greater 
Table 2 Clinical presentation of the individualised 1:1 physiotherapy outpatient intervention participants (baseline data)

\begin{tabular}{|c|c|c|c|}
\hline \multicolumn{2}{|l|}{ Measure } & $\mathrm{n}^{*}$ & Participants \\
\hline \multicolumn{2}{|c|}{ Duration of symptoms prior to surgery (mean months, \pm SD) } & 29 & $68.34 \pm 93.80$ \\
\hline \multirow[t]{6}{*}{ Nature of symptoms prior to surgery $n(\%)$} & Back pain (number) & 29 & $22(76)$ \\
\hline & Leg pain (number) & 29 & $27(93)$ \\
\hline & Paraesthesia & 29 & $18(62)$ \\
\hline & Numbness & 29 & $21(72)$ \\
\hline & Weakness & 29 & $14(48)$ \\
\hline & Cauda equina & 29 & $4(14)$ \\
\hline \multicolumn{2}{|l|}{ Currently taking pain relief (yes:no) } & 28 & $22: 6$ \\
\hline \multicolumn{2}{|c|}{ Roland Morris Disability Questionnaire (range, mean, \pm SD) } & 29 & 0 to $23,10.52 \pm 5.94$ \\
\hline \multicolumn{2}{|c|}{ Global Perceived Effect (median, IQR) } & 29 & 2,1 \\
\hline \multirow[t]{3}{*}{ VAS Back Pain (mean, \pm SD) } & Today & 29 & $2.30(1.80)$ \\
\hline & Least in last $2 / 52$ & 29 & $1.48(1.31)$ \\
\hline & Greatest in last 2/52 & 28 & $4.80(3.06)$ \\
\hline \multirow[t]{3}{*}{ VAS Leg Pain (mean, $\pm S D$ ) } & Today & 28 & $1.62(2.13)$ \\
\hline & Least in last $2 / 52$ & 28 & $0.84(1.55)$ \\
\hline & Greatest in last 2/52 & 28 & $3.74(2.93)$ \\
\hline \multicolumn{2}{|l|}{ TAMPA (mean, $\pm S D$ ) } & 29 & $40.48(6.47)$ \\
\hline \multicolumn{2}{|l|}{ FABQ physical activity (mean, $\pm \mathrm{SD}$ ) } & 27 & $13.15(4.52)$ \\
\hline \multicolumn{2}{|l|}{$\mathrm{FABQ}$ work (mean, $\pm \mathrm{SD}$ ) } & 26 & $19.96(11.15)$ \\
\hline \multicolumn{2}{|l|}{ EQ5D 5L (VAS): Health today (mean \pm SD) } & 29 & $71.61(16.50)$ \\
\hline \multirow[t]{5}{*}{ EQ5D 5L (median (IQR) min, max) } & Mobility & 29 & $2(1) 1,4$ \\
\hline & Self-care & 29 & $1(1) 1,3$ \\
\hline & Usual activities & 29 & $3(1.5) 1,5$ \\
\hline & Pain/discomfort & 29 & $3(1) 1,4$ \\
\hline & Anxiety/depression & 29 & $2(1.5) 1,5$ \\
\hline \multirow[t]{4}{*}{ Range of movement degrees (mean, $\pm \mathrm{SD}$ ) } & Flexion & 29 & $3.54(1.96)$ \\
\hline & Extension & 29 & $0.71(3.40)$ \\
\hline & Left side flexion & 29 & $31.56(17.96)$ \\
\hline & Right side flexion & 29 & $30.71(17.89)$ \\
\hline \multicolumn{2}{|c|}{ Straight leg raise test: angle of symptomatic leg (mean, $\pm S D$ ) } & 29 & $66.64(18.02)$ \\
\hline Straight leg raise $\mathrm{n}(\%)$ & Test positive & 27 & $25(86)$ \\
\hline \multirow[t]{3}{*}{ Straight leg raise test Limiting Factor $n(\%)$} & Pain & 27 & $14(48)$ \\
\hline & Resistance & 27 & $11(38)$ \\
\hline & Pain and resistance & 27 & $2(7)$ \\
\hline
\end{tabular}

*Some missing data.

FABQ, Fear Avoidance and Beliefs Questionnaire; VAS, Visual Analogue Scale.

Table 3 Baseline STarT Back data individualised 1:1 physiotherapy outpatient intervention participants $(n=29)$

\begin{tabular}{ll}
\hline STarT Back item & $\mathbf{n}(\%)$ \\
\hline $\begin{array}{l}\text { My back pain has spread down my leg(s) at } \\
\text { some time in the last } 2 \text { weeks }\end{array}$ & $19(66)$ \\
I have only walked short distances because of & $17(59)$ \\
my back pain & \\
In the last 2 weeks, I have dressed more slowly & $14(48)$ \\
than usual because of back pain \\
I feel that my back pain is terrible and it's never \\
going to get any better \\
$\begin{array}{l}\text { In general I have not enjoyed all the things I used } \\
\text { to enjoy (number) }\end{array}$ \\
$\begin{array}{l}\text { Overall, how bothersome has your back pain } \\
\text { been in the last } 2 \text { weeks? }\end{array}$ \\
$\begin{array}{l}\text { Number of participants scoring } 3 \text { or above-not } \\
\text { at low risk of chronicity/poor outcome (criteria for } \\
\text { referral to physiotherapy) }\end{array}$ \\
$\begin{array}{l}\text { Six-item STarT Back total score (median, IQR) } \\
\text { (31) }\end{array}$ \\
\hline
\end{tabular}

number of problems. Patients with a greater number of problems required more treatment sessions (table 5).

The identified clinical problems were detailed within the framework of the 1:1 physiotherapy intervention (table 6). The most common problem was reduced trunk stabilisation.

The treatments employed by physiotherapists to manage the identified problem are detailed in online supplementary file S2. As treatment progressed, only one participant was documented with a problem of not responding/condition deteriorating/experiencing complications. This participant was not initially identified as requiring caution, but did present with the highest number of problems $(n=9)$ and STarT Back not at low risk. Reduced progress/plateau in improvement was identified as a problem for 4 patients $(n=2$ were STarT Back not at low risk and $n=1$ had a problem of impaired recovery owing to psychological factors). Only two participants were evaluated as 
Table 4 Physiotherapist diagnosis

\begin{tabular}{|c|c|}
\hline Nature of diagnosis & Specific detail from individual participants $(n=22)$ \\
\hline $\begin{array}{l}\text { Broad diagnosis-mechanical low back } \\
\text { pain } \\
\text { Post surgical diagnosis- } \\
\text { microdiscectomy }\end{array}$ & $\begin{array}{l}\text { Mechanical LBP_resolving non-capsular disc lesion post surgery } \\
\text { Mechanical LBP post surgery } \\
6 / 52 \text { postright sided L4/5 Microdiscectomy } \\
\text { Right L4/5 Microdiscectomy } \\
\text { Right L4/5 Microdiscectomy } \\
\text { Left L5/S1 Microdiscectomy } \\
\text { Residual LBP with slight increase pain left side post microdiscectomy } \\
\text { Resolving Radicular pain post-L4/5 microdiscectomy. Congenital scoliosis with } \\
\text { rotation. Leg length discrepancy following surgery for right club foot and left hip } \\
\text { dysplasia as child } \\
\text { L5/S1 Microdiscectomy. Deconditioning post surgery } \\
\text { L5/S1 microdiscectomy } \\
\text { L5/S1 microdiscectomy with residual S1 weakness and decreased sensation }\end{array}$ \\
\hline Post surgical diagnosis—discectomy & $\begin{array}{l}\text { Right L3 Decompression } \\
\text { L4/5 discectomy, fenestration and laminectomy } \\
\text { L45 discectomy } \\
\text { L5-S1 Fenestration and Discectomy } \\
\text { 5/52 postleft L5/S1 discectomy_residual stiffness }\end{array}$ \\
\hline $\begin{array}{l}\text { Diagnosis related to problems- } \\
\text { presenting clinical problems }\end{array}$ & $\begin{array}{l}\text { Post-op back stiffness, poor core stability } \\
\text { Increased adverse neural tension into right leg, lumbar spine stiffness } \\
\text { Post-op stiffness } 5 / 52 \text { post surgery } \\
\text { Post-op stiffness } \\
\text { Left facet tightness/stiffness } \\
\text { Residual weakness right glut max and med }\end{array}$ \\
\hline
\end{tabular}

LBP, low back pain.

having a problem of psychological factors affecting recovery.

\section{Number of treatment sessions}

The mean (SD) number of treatment sessions was 3.14 (1.16), range of 1-6 (figure 2). No participant required the maximum of eight sessions. Table 7 illustrates that participants classified as STarT Back not at low risk, and participants requiring caution required a greater number of treatment sessions.

Participants demonstrated $100 \%$ adherence at 12 weeks, although the nature of adherence did vary and was affected by factors that included their motivation. Some participants reported exercising three times per day and others 'as able to' around other activities such as work or gym. Participants provided reasons for reducing their exercises including: pain, increasing other activities such as golf and walking, cycling, or returning to work; but also increasing exercises, for example, exercising in response to days of increased pain.

\section{Patient outcome data}

Table 8 details the patient outcome data at baseline and at 12 weeks after completion of the optimised intervention.

For the primary outcome measure the RMDQ, sensitivity to change was assessed at 12 weeks with mean (SD) change -6.18 (5.59), $95 \%$ CI -9.01 to -3.30 for the individualised 1:1 physiotherapy outpatient intervention. Full data and statistical analysis is reported elsewhere. ${ }^{16}$
Table 5 Number of problems Identified by physiotherapists

\begin{tabular}{|c|c|c|c|}
\hline & & $\begin{array}{l}\text { Mean no of } \\
\text { problems }\end{array}$ & SD \\
\hline \multicolumn{2}{|l|}{ All 22 participants } & 5.36 & 2.63 \\
\hline \multicolumn{2}{|l|}{ Male $(n=15)$} & 5.07 & 2.74 \\
\hline \multicolumn{2}{|l|}{ Female $(n=7)$} & 6.00 & 2.45 \\
\hline Age (missing & $<45$ years $(n=10)$ & 5.50 & 2.59 \\
\hline data $n=2)$ & $\geq 45$ years $(n=10)$ & 5.40 & 2.55 \\
\hline \multicolumn{2}{|c|}{ StarT Back low risk $(n=11)$} & 4.36 & 2.16 \\
\hline \multicolumn{2}{|c|}{ STarT Back not at low risk $(n=11)$} & 6.36 & 2.77 \\
\hline \multicolumn{2}{|l|}{ Caution $(n=8)$} & 6.50 & 1.41 \\
\hline \multicolumn{2}{|c|}{ No Caution $(n=14)$} & 4.71 & 2.97 \\
\hline \multirow{2}{*}{$\begin{array}{l}\text { No of treatment } \\
\text { sessions }\end{array}$} & $1-3$ sessions $(n=13)$ & 3.77 & 2.09 \\
\hline & $4-6$ sessions $(n=9)$ & 7.67 & 1.23 \\
\hline
\end{tabular}

\section{Patient discharge data}

Of the treating physiotherapists who included their assessment of the patient's status at discharge $(n=12)$, all felt that the patient had improved. The data highlights that $n=3$ patients required further care (see online supplementary file S3).

\section{DISCUSSION}

\section{Participants}

The mean duration of symptoms prior to surgery of 68 months is substantial and illustrates the chronic nature of patients. Their clinical presentation was characteristic of 
Table 6 Number of participants presenting with each problem

\begin{tabular}{ll}
\hline Problem & $\begin{array}{l}\text { No of participants } \\
\text { with problem }(\mathbf{n = 2 2})\end{array}$ \\
\hline Reduced trunk stabilisation & 20 \\
Reduced spinal ROM & 17 \\
Inadequate knowledge to enable & 16 \\
self-management & 14 \\
Reduced conditioning/fitness & 12 \\
Reduced functional mobility & 12 \\
Pain & 10 \\
Reduced general strength & 10 \\
Reduced neural mobility & 4 \\
Reduced progress/plateau in & \\
improvement & 2 \\
Impaired recovery owing to & \\
psychological factors & 1 \\
Patient not responding to & \\
treatment/deteriorating/ & \\
complications & \\
\hline ROM, range of movement. &
\end{tabular}

disc problems affecting the nerve roots with all patients presenting with pain and the majority with leg pain (93\%); most accompanied with paraesthesia and numbness. The mean age of participants of 44 years emphasises the importance of returning to work/function. The demographic profile closely resembles the populations in existing clinical trials, ${ }^{3} 12$ and wider UK data. ${ }^{4}$

At 4 weeks post surgery (optimal intervention timing) ${ }^{312}$ in the subacute stage of healing, participants were characterised by moderate disability (mean RMDQ 10.52 ), and although pain was of overall low severity, most still required analgesia. There was considerable variability in disability (range 0-23, SD 5.94) highlighting heterogeneity of this population. While the median GPE of 2 and high health related quality of life scores reflected considerable improvement from surgery,

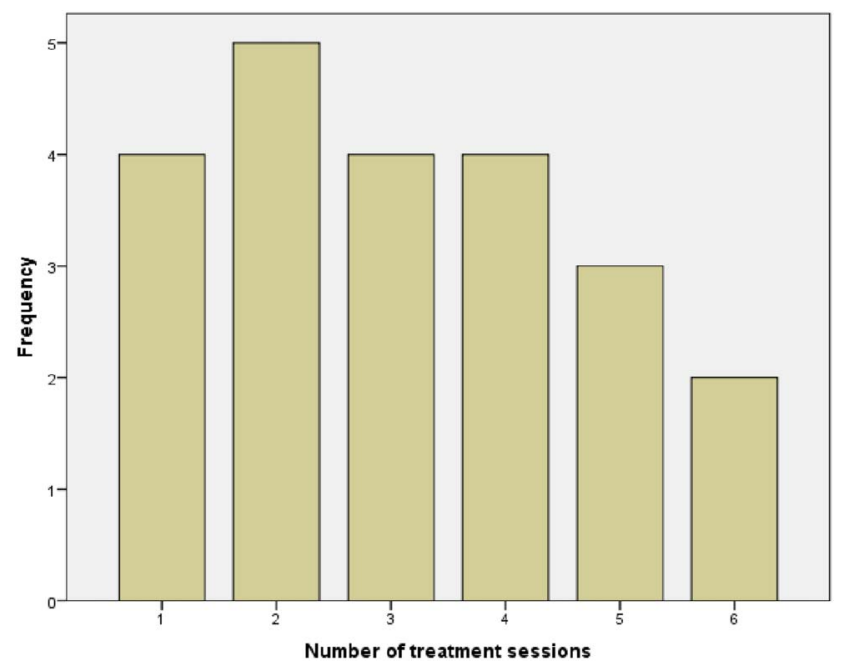

Figure 2 Number of treatment sessions.
Table 7 Number of treatment sessions provided by physiotherapists

\begin{tabular}{lll}
\hline & $\begin{array}{l}\text { Mean no of } \\
\text { treatment } \\
\text { sessions }\end{array}$ & SD \\
\hline All 22 participants & 3.14 & 1.61 \\
Male $(n=15)$ & 3.07 & 1.58 \\
Female $(n=7)$ & 3.29 & 1.80 \\
Age (missing <45 years $(n=10)$ & 3.20 & 1.48 \\
data $n=2) \quad \geq 45$ years $(n=10)$ & 3.20 & 1.81 \\
STarT Back low risk $(n=11)$ & 2.64 & 1.12 \\
STarT Back not at low risk $(n=11)$ & 3.64 & 1.91 \\
Caution $(n=8) \quad 4.00$ & 1.85 \\
No caution $(n=14)$ & 2.64 & 1.28 \\
\hline
\end{tabular}

participants did present with high kinesiophobia. The mean TAMPA of 40.48 (SD 6.47) was $\geq 37$, the recommended cut-off. ${ }^{28}$ This may reflect a lack of confidence in returning to function following surgery. In contrast, the mean (SD) FABQ activity score of 13.15 (4.52) and FABQ work of 19.96 (11.15) were not elevated according to preliminary data regarding cut-off scores. ${ }^{29} 30$ These differences are interesting as some overlap between these two measures in a chronic LBP population is proposed, and a strong relationship exists between disability and increased FABQ. ${ }^{31}$

Use of STarT Back suggested that at baseline, $55 \%$ of participants required physiotherapy; being evaluated not at low risk of poor outcome. Physiotherapy evaluation designated other patients as requiring caution in their management, and others with multiple problems that were not detected using STarT Back. Leg pain-a question on STarT Back is the main indicator for lumbar discectomy and so this may have affected the data, reflecting an obvious limitation of STarT Back in this population. Interestingly, five of seven patients who did not attend for physiotherapy were classified as low risk of poor outcome which may have informed their decision not to attend. This is the first time the STarT Back tool has been used in secondary care with post operative patients, as previous secondary care studies excluded post operative patients ${ }^{23}$ or included a broad range of conditions. ${ }^{24}{ }^{26}$ The STarT Back tool has less predictive ability in secondary care but its performance equals alternative measures. ${ }^{26}$ Overall, STarT Back may therefore be useful in combination with other factors to inform decisions regarding patients that require more than minimal physiotherapy intervention. This merits further investigation to explore potential stratification of this population.

\section{Physiotherapist clinical reasoning}

Diagnosis and caution

Physiotherapists used a range of diagnostic categories following their assessment of patients, with most focused on the surgical procedure, distinguishing discectomy, 
Table 8 Outcome data at baseline (4 weeks post surgery) and 12 weeks (post intervention)

\begin{tabular}{|c|c|c|c|}
\hline \multicolumn{2}{|l|}{ Outcomes } & \multirow{2}{*}{$\begin{array}{l}\begin{array}{l}\text { Baseline } \\
\text { n Mean (SD) }\end{array} \\
2910.52(5.94)\end{array}$} & \multirow{2}{*}{$\begin{array}{l}12 \text { weeks } \\
\text { n Mean (SD) } \\
175.53(4.49)\end{array}$} \\
\hline Roland Morris Disability Question & & & \\
\hline \multirow{3}{*}{ VAS Back Pain } & Today & $292.30(1.80)$ & $172.20(1.65)$ \\
\hline & Least in last 2/52 & $291.48(1.31)$ & $171.70(1.60)$ \\
\hline & Greatest in last 2/52 & $284.80(3.06)$ & $174.34(2.64)$ \\
\hline \multirow[t]{3}{*}{ VAS Leg Pain } & Today & $281.62(2.13)$ & $171.74(2.13)$ \\
\hline & Least in last 2/52 & $280.84(1.55)$ & $171.79(2.50)$ \\
\hline & Greatest in last 2/52 & $283.74(2.93)$ & $173.64(2.82)$ \\
\hline \multicolumn{2}{|l|}{ Tampa Scale for Kinesiophobia } & $2940.48(6.47)$ & $1737.35(8.29)$ \\
\hline \multicolumn{2}{|c|}{ Fear Avoidance and Beliefs Questionnaire physical activity } & $2713.15(4.52)$ & 1511.53 (7.73) \\
\hline \multicolumn{2}{|c|}{ Fear Avoidance and Beliefs Questionnaire work } & 2619.96 (11.15) & $1416.86(12.48)$ \\
\hline EQ5D 5L (VAS): Health today & & $2971.61(16.50)$ & $1770.06(10.58)$ \\
\hline \multirow[t]{4}{*}{ Range of movement } & Flexion & $293.54(1.96)$ & $174.47(1.49)$ \\
\hline & Extension & $290.71(3.40)$ & $171.64(3.96)$ \\
\hline & Left side flexion & 2931.56 (17.96) & $1535.59(17.97)$ \\
\hline & Right side flexion & $2930.71(17.89)$ & 1532.49 17.38) \\
\hline \multirow[t]{2}{*}{ Straight leg raise } & Angle of symptomatic leg & $2966.64(18.02)$ & $1780.53(12.53)$ \\
\hline & & $\mathrm{n}(\%)$ & $\mathrm{n}(\%)$ \\
\hline Straight leg raise & Test positive & $25(86)$ & $9(53)$ \\
\hline \multirow[t]{5}{*}{ Straight leg raise limiting factor } & Pain & $14(48)$ & $4(24)$ \\
\hline & Resistance & $11(38)$ & $9(53)$ \\
\hline & Pain and resistance & $2(7)$ & $0(0)$ \\
\hline & Missing & $2(7)$ & $4(24)$ \\
\hline & & $\mathrm{n}(\%)$ & $\mathrm{n}(\%)$ \\
\hline \multirow[t]{6}{*}{ Return to work } & Yes & $8(28)$ & $10(59)$ \\
\hline & No & $19(56)$ & $5(30)$ \\
\hline & Not applicable & $1(3)$ & $2(12)$ \\
\hline & Full-time & $6(21)$ & $8(47)$ \\
\hline & Part-time & $2(7)$ & $2(12)$ \\
\hline & Not applicable & $21(72)$ & $7(41)$ \\
\hline \multirow[t]{3}{*}{ Type of duties on return to work } & Full duties & $3(10)$ & $7(41)$ \\
\hline & Light duties & $4(14)$ & $3(18)$ \\
\hline & No or not applicable & $22(76)$ & $7(41)$ \\
\hline \multirow[t]{3}{*}{ Return to normal activities } & Yes & $7(24)$ & $11(65)$ \\
\hline & No & $22(76)$ & $6(35)$ \\
\hline & & N Mean (SD) & \\
\hline \multicolumn{2}{|c|}{ Return to work: weeks post surgery mean (SD) } & $83.81(1.60)$ & $107.8(4.71)$ \\
\hline \multirow{2}{*}{\multicolumn{2}{|c|}{ Return to normal activities: weeks post surgery }} & $73.21(1.63)$ & $118.18(4.51)$ \\
\hline & & n (median, IQR) & n (median, IQR) \\
\hline \multicolumn{2}{|c|}{ Global Perceived Effect (median, range) } & $29(2,1)$ & $16^{\star}(2,0.75)$ \\
\hline
\end{tabular}

microdiscectomy and level of procedure; reflecting a biomedical approach. The most common levels were low lumbar specifically $\mathrm{L}_{4,5}, \mathrm{~S}_{1}$. Physiotherapists designated $\mathrm{n}=8$ participants as requiring caution, the main reason being a risk of overdoing activity at a time when tissues are still healing; and this evaluation did not reflect STarT Back. This does suggest, unsurprisingly that STarT Back is not focused on all relevant issues for this population, and that the intervention framework facilitated further discrimination between patients.

\section{Participants' problems}

The mean of 5.36 (SD 2.63) problems highlighted the substantive issues still experienced by participants
4 weeks following surgery. The higher number of problems was consistent with the physiotherapist reasoning around caution and STarT Back not at low risk. The nature of the identified problems reflected the chronicity and complexity of patients undergoing surgery, and therefore the requirement of intervention to support their ability to self-manage. The nature of problems reflected a focus on function with the key issues being muscle strength, range of movement, general conditioning and fitness.

Physiotherapy treatment

Clarity of a framework for the intervention ${ }^{15}$ perhaps contributed to a consistent approach to physiotherapy 
management that did not reflect previously identified variability. ${ }^{11}$ Treatments reflected an emphasis on education, advice and progressing activity and function, with the use of manual therapy, specific exercises, and general exercise interventions. Reduced neural mobility was identified as a problem for $n=10$ participants but few specific treatment interventions were implemented; suggesting that neural symptoms resolved through other interventions/time. There was an emphasis on progression of management, for example, exercises for an individual, but not the emphasis on high intensity exercises within the literature $;{ }^{312}$ perhaps limited by the exclusion of exercise class interventions in this study. Psychological issues were only identified for $n=2$ participants and so psychologically informed interventions were not widely used (cognitivebehavioural approaches, pacing or goal setting). This suggests that physiotherapists were happy using education, advice and other interventions to address kinesiophobia. The number of physiotherapy sessions ranging 1-6 was not reflective of the UK survey of 1-20 sessions perhaps reflecting a change in more recent practice. ${ }^{11}$ The physiotherapists reasoned that participants with a greater number of problems, or in situations where caution was required, needed a greater number of sessions.

\section{Outcome data}

The data demonstrate that participants improved in most outcomes by 12 weeks. In particular, the return to work data was promising with $59 \%$ participants back at work and $65 \%$ back to usual activities by 12 weeks compared to $28 \%$ and $24 \%$ at baseline. This compares to $70 \%$ fit to return to work 12 months after surgery. ${ }^{7}$ For the RMDQ, sensitivity to change at 12 weeks was promising. These positive outcomes were reflected in the physiotherapists' discharge summaries, and physiotherapists identified that $n=3$ participants required further management, identifying a small number of participants who required greater intervention than the defined parameters. Although improved, an issue that requires further consideration is kinesiophobia as at 12 weeks the TAMPA remained close to the $\geq 37$ cut-off. $^{28}$

\section{Limitations}

While some potentially interesting differences between participants are highlighted and areas for further investigation identified, it is difficult to draw meaningful conclusions from this data owing to the low number of participants. To reflect current practice, the nine-item STarT Back may have been more valuable to avoid reducing the tool's discriminative power. ${ }^{25}$ Although specific interventions were indicated as used, free text sections were often left unanswered thereby limited depth of information was gained. It is difficult to establish whether this represents a training issue regarding data collection, or the increasing demands placed on NHS physiotherapists. The wide inclusion of all bands of physiotherapist, with some less experienced in managing this population, may also have contributed to these issues.

\section{CONCLUSIONS}

These data suggest that patients present differently postlumbar discectomy and therefore require different interventions. These differences can be identified by clinical reasoning and a tool such as STarT Back, although the congruence between the two merits further consideration, and these findings merit further investigation in a larger sample. The crux of this issue is the identification and targeted treatment of patients to ensure that patients at low risk of poor outcome are not over treated and patients not at low risk of poor outcome are not under treated. This is a key issue in this climate of austerity and the move towards more resourceful healthcare, improving quality and safety, and minimising costs by avoiding unnecessary treatment. ${ }^{32}$

\section{Author affiliations}

${ }^{1}$ School of Sport, Exercise and Rehabilitation Sciences, University of Birmingham, Birmingham, UK

${ }^{2}$ Department of Physiotherapy, Aneurin Bevan University Health Board, Ebbw Vale, UK

${ }^{3}$ University Hospitals Birmingham NHS Foundation Trust, Queen Elizabeth Hospital, Birmingham, UK

${ }^{4}$ Institute of Applied Health Research, College of Medical and Dental Sciences, University of Birmingham, Birmingham, UK

${ }^{5}$ Health Professions Department (Physiotherapy), Manchester, UK

Acknowledgements Claire Littleford and Christopher Bayliss, patient users. Christine Wright, who was initially the study statistician prior to retirement.

Contributors $A R$ and $P G$ are Senior Lecturers in physiotherapy and NH is a lecturer in physiotherapy. $M C$ is a Professor of outcomes methodology. AC, $\mathrm{AH}$ and $\mathrm{LW}$ are clinical specialists and extended scope practitioners working in spinal surgery. AR, PG, NH, AC, AH and LW have long-standing professional interests in the rehabilitation of patients following spinal surgery, and all have a professional focus to musculoskeletal physiotherapy. AR, PG, $A H$ and $L W$ were responsible for the conception of the study. AR, MC, PG and $\mathrm{NH}$ were responsible for the design and methodology. $\mathrm{AR}, \mathrm{AC}$ and $\mathrm{NH}$ were responsible for the data analysis. All authors have contributed to the study and have been involved in developing the content of the article. AR and AC wrote the first draft of the paper. AR has worked with all authors reworking content into subsequent drafts. All authors gave final approval of the version to be published. AR is the guarantor.

Funding Queen Elizabeth Hospital Birmingham Charity, Birmingham, UK to support the costs of developing and evaluating the intervention. Project 17-3-780.

Competing interests None declared.

Ethics approval West Midlands - Solihull Research Ethics Committee.

Provenance and peer review Not commissioned; externally peer reviewed.

Data sharing statement No additional data are available.

Open Access This is an Open Access article distributed in accordance with the Creative Commons Attribution Non Commercial (CC BY-NC 4.0) license, which permits others to distribute, remix, adapt, build upon this work noncommercially, and license their derivative works on different terms, provided the original work is properly cited and the use is non-commercial. See: http:// creativecommons.org/licenses/by-nc/4.0/

\section{REFERENCES}

1. WHO. The burden of musculoskeletal conditions at the start of the new millennium. World Health Organisation, Geneva, 2003.

2. Maniadakis N, Gray A. The economic burden of back pain in the UK Pain 2000;84:95-103. 
3. Oosterhuis T, Costa LO, Maher CG, et al. Rehabilitation after lumbar disc surgery (review). Cochrane Database Syst Rev 2014;(3):CD003007.

4. HES online All procedures and interventions 2013/14. 3 character. All procedures [V33]. http://www.hscic.gov.uk/hes (accessed 3 Mar 2015).

5. van Beek E, Lemmens K, van Schooten G, et al. Reduceren van praktijkvariatie: budgettaire effecten van scherpere indicatiestelling. Breukelen: Plexus, 2010.

6. Sherman J, Cauthen J, Schoenberg D, et al. Economic impact of improving outcomes of lumbar discectomy. Spine J 2010;10:108-16.

7. Donceel P, Du Bois M. Predictors for work incapacity continuing after disc surgery. Scand J Work Environ Health 1999;25:264-71.

8. Ostelo RW, Goossens ME, de Vet HC, et al. Economic evaluation of behavioural-graded activity program compared to physical therapy for patients following lumbar disc surgery. Spine (Phila Pa 1976) 2004;29:615-22.

9. СВO. The lumbosacral radicular syndrome, Dutch Institute for Healthcare Improvement. Centraal Begeleidings Orgaan Report. 2008.

10. McGregor AH, Dicken B, Jamrozik K. National audit of post-operative management in spinal surgery. BMC Musculoskelet Disord 2006;7:47.

11. Williamson E, White L, Rushton A. A survey of post-operative management for patients following first time lumbar discectomy. Eur Spine J 2007;16:795-802.

12. Rushton A, Wright C, Goodwin P, et al. Physiotherapy rehabilitation post first lumbar discectomy: a systematic review and meta-analysis of randomised controlled trials. Spine (Phila Pa 1976) 2011;36: E961-72.

13. Ostelo RW, Costa LO, Maher CG, et al. Rehabilitation after lumbar disc surgery. Cochrane Database Syst Rev 2008;(4):CD003007.

14. Rushton A, White L, Heap A, et al. Development of $1: 1$ physiotherapy intervention post first-time lumbar discectomy. BMJ Open 2016;6:e009409.

15. Craig $P$, Dieppe $P$, Macintyre $S$ et al. Developing and evaluating complex interventions: the new Medical Research Council guidance. BMJ 2008;337:a1655.

16. Rushton A, Heneghan N, Calvert M, et al. Physiotherapy Post Lumbar Discectomy: Prospective Feasibility and Pilot Randomised Controlled Trial. PLOS ONE 2015;10:e0142013.

17. Selkowitz DM, Kulig K, Poppert EM, et al., Physical Therapy Clinica Research Network. The immediate and long term effects of exercise and patient education on physical, functional, and quality of life outcome measures after single level lumbar microdiscectomy: a randomized controlled trial protocol. BMC Musculoskelet Disord 2006;7:70.
18. Foster MR. Herniated disc prolapse. eMedicine.com, 2007. http:// www.emedicine.com/orthoped/topic138.htm (accessed 14 Feb 2016).

19. Barrios C, Ahmed M, Arrótegui J, et al. Microsurgery versus standard removal of the herniated lumbar disc A 3-year comparison in 150 cases. Acta Orthop Scand 1990;61:399-403.

20. Goodwin PC, Wright CC, Allan C, et al. Evidence-based development of a post-surgical lumbar discectomy leaflet intervention: a Delphi consensus study. BMJ Open 2015;5:e006069.

21. Hill JC, Dunn KM, Lewis M, et al. A primary care back pain screening tool: Identifying patient subgroups for initial treatment. Arthritis Rheum 2008;59:632-41.

22. Hill JC, Dunn KM, Main CJ, et al. Subgrouping low back pain: a comparison of the STarT Back Tool with the Orebro Musculoskeletal Pain Screening Questionnaire. Eur J Pain 2010;14:83-9.

23. Fritz JM, Beneciuk JM, George SZ. Relationship between categorization with the STarT Back Screening Tool and prognosis for people receiving physical therapy for low back pain. Phys Ther 2011;91:722-32.

24. Beneciuk JM, Bishop MD, Fritz JM, et al. The STarT Back Screening Tool and individual psychological measures: Evaluation of prognostic capabilities for low back pain clinical outcomes in outpatient physical therapy settings. Phys Ther 2013;93:321-33

25. Morsø L, Kent P, Albert HB, et al. Is the psychosocial profile of people with low back pain seeking care in Danish primary care different from those in secondary care? Man Ther 2013;18:54-9.

26. Mors $ø \mathrm{~L}$, Kent $\mathrm{P}$, Manniche $\mathrm{C}$, et al. The predictive ability of the STarT Back Screening Tool in a Danish secondary care setting. Eur Spine J 2014;23:120-8.

27. Sim J, Wright C. Research in health care: concepts, designs, and methods. Cheltenham, England: Stanley Thornes, 2000.

28. Vlaeyen JW, Kole-Snijders AM, Boeren RG, et al. Fear of movement/(re) injury in chronic low back pain and its relation to behavioral performance. Pain 1995;62:363-72.

29. Crombez G, Vlaeyen JW, Heuts PH, et al. Pain-related fear is more disabling than pain itself: evidence on the role of pain-related fear in chronic back pain disability. Pain 1999;80:329-39.

30. Fritz JM, George SZ. Identifying psychosocial variables in patients with acute work-related low back pain: the importance of fear-avoidance beliefs. Phys Ther 2002;82:973-83.

31. George SZ, Calley D, Valencia C, et al. Clinical investigation of pain-related fear and pain catastrophizing for patients with low back pain. Clin J Pain 2011;27:108-15.

32. Bradley P, Wilson A. Achieving prudent healthcare in NHS Wales (revised). Cardiff: Public Health Wales, 2014. 